\title{
Copolymers Formation by Photopolymerization of (Meth)acrylates Containing Dissolved Polyheteroarylenes
}

\author{
Dmitriy A. Sapozhnikov, ${ }^{1,2}$ Tat'yana V. Volkova, ${ }^{1}$ Antonina A. Sakharova, ${ }^{1}$ \\ Rashid G. Gasanov, ${ }^{1}$ Vanda Yu. Voytekunas, ${ }^{2}$ Marc J. M. Abadie, ${ }^{2}$ \\ Jean-Yves Sanchez, ${ }^{3}$ and Yakov S. Vygodskii ${ }^{1}$ \\ ${ }^{1}$ A. N. Nesmeyanov Institute of Organoelement Compounds, Russian Academy of Sciences, Vavilov str. 28, 119991 Moscow, Russia \\ ${ }^{2}$ LEMP-MAO, CC 021, Université Montpellier 2, Pl. E.Bataillon, 34095 Montpellier, France \\ ${ }^{3}$ LEPMI ENSEEG, UMR 5631 CNRS-INPG-UJF, Domaine Universitaire, BP 75, 38402 Saint Martin d'Hères Cedex, France
}

Correspondence should be addressed to Yakov S. Vygodskii, yasvyg@ineos.ac.ru

Received 6 November 2008; Revised 19 February 2009; Accepted 27 April 2009

Recommended by Geoffrey R. Mitchell

Radical photopolymerization of (meth)acrylates in the presence of dissolved polyheteroarylenes has been investigated. The kinetics of radical polymerization of unsaturated monomers in the presence of polyheteroarylenes and model compounds has been studied by Differential Scanning Photocalorimetry and Infrared Spectroscopy. From the results of investigations into the kinetics and the polymer structures (Fourier Transform Infrared Spectroscopy, Nuclear Magnetic Resonance, Size-exclusion Chromatography, Thermogravimetric analysis), it has been established that radical photopolymerization of vinyl monomers in the presence of polyheteroarylenes leads to the formation of copolymers owing to chain transfer reactions and/or chain termination by the relevant condensation polymer. Using Electron Spin Resonance Spectroscopy the novel radicals upon the addition of model compounds for the polyheteroarylenes have been detected, and a mechanism of copolymer formation has been proposed.

Copyright (C) 2009 Dmitriy A. Sapozhnikov et al. This is an open access article distributed under the Creative Commons Attribution License, which permits unrestricted use, distribution, and reproduction in any medium, provided the original work is properly cited.

\section{Introduction}

Earlier we established that polyheteroarylenes (polyimides, aromaric polyesters, etc.) containing perfluoroalkylene, mainly $\left[\mathrm{C}\left(\mathrm{CF}_{3}\right)_{2}\right]$ moieties, and/or cardo groups have excellent solubility in organic solvents and several vinyl monomers (methyl methacrylate, ethyl acrylate, etc.). This served as the basis for studying the possibility of formulating new polymeric systems by polymerization of vinyl monomers containing dissolved polyheteroarylenes.

Research into the radical thermal polymerization of acrylates [1-4] and styrene [5] containing dissolved polyheteroarylenes (PHA), including the three-dimensional copolymerization of methyl methacrylate (MMA) with various difunctional monomers $[6,7]$, has shown the possibility to synthesize copolymers containing fragments of polyheteroarylenes and of carbon-chain polymers based on the vinyl monomers. In previous work using styrene as the vinyl monomer it has been established that the styrene homopolymer is not formed even in the presence of only a small (4 wt\%) content of polyimide (PI) in the monomer [5].

The photoinitiated polymerization of vinyl monomers in the presence of dissolved polyheteroarylenes has been investigated in order to define the universality of the abovestated approach to formation of copolymers. This research is also the result of new potential applications having opened for the photopolymerization processes including lithography [8], coatings [9], printed equipment, and nonlinear optics. [10-12]. Some previous interesting results on the photopolymerization of MMA in the presence of PI [13] also motivated us to pursue this research.

\section{Experimental}

2.1. Materials. Vinyl monomers, solvents, and monomers for the synthesis of polyheteroarylenes and model Diimide were purified by literature methods [3]. Photoinitiator (Pht) IRGACURE-1700 was supplied by CIBA-GEIGY 


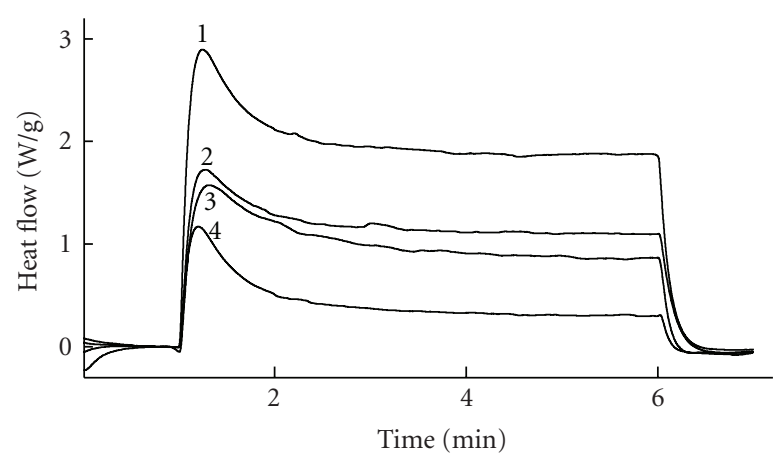

(a)

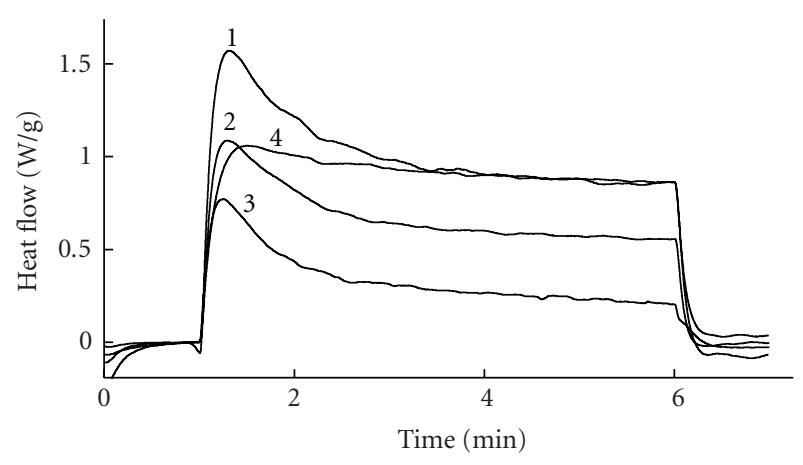

(b)

FIGURE 1: DSPC thermograms for photopolymerization. (a) 1: MMA, 2-4: MMA containing 5 wt.\% of Diimide, PI 2 and PI 1; (b) MMA containing 5 (1), 10 (2), 20 (3), and 42 wt.\% of PI 2 (4).

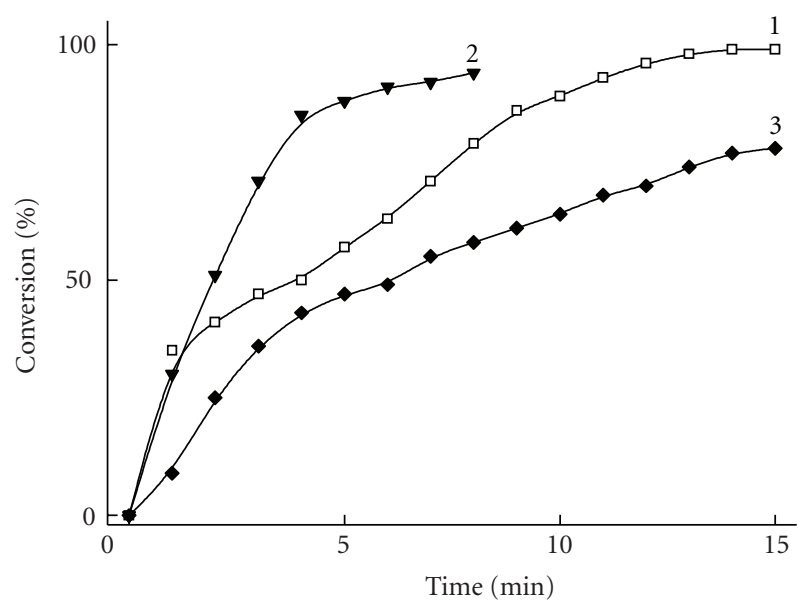

Figure 2: MMA conversion on irradiation time. 1: MMA $+5 \mathrm{wt} \%$ Pht, 2: MMA + $5 w t \%$ Pht $+10 w t \%$ PI 1, 3: MMA + $5 w t \%$ Pht + $10 \mathrm{wt} \%$ Diimide.

and used as received. Ethyl 2-bromopropionate, nitrosodurene (ND), 2-methyl-2-nitrosopropane (MNP), 2,2' -azobis-isobutyronitrile $(\mathrm{AIBN})$, and $\left[\operatorname{Re}(\mathrm{CO})_{5}\right]_{2}$ were used as received from Aldrich or Acros Organics.

2.2. Polyheteroarylenes and Model Compounds. Synthesis of Diimide, PI, and polyarylate (PAr) is described in $[4,14]$. In the present work we used PI 1 with $\eta_{\text {inh }}=1.24 \mathrm{dL} \mathrm{g}^{-1}$ (N-methylpyrrolidinone), PI 2 with $\eta_{\text {inh }}=0.29 \mathrm{dL} \mathrm{g}^{-1}$ (dimethylformamide), and PAr with $\eta_{\text {inh }}=0.71 \mathrm{dL} \mathrm{g}^{-1}(\mathrm{~N}-$ methylpyrrolidinone).

2.3. Differential Scanning Photocalorimetry (DSPC). DSPC studies were performed on a DuPont 930 apparatus with a double heat differential calorimeter 912. Used experimental technique was given in details [13]. The average of two obtained kinetic results values with the calculated error is presented in the tables because of high sensitivity of a Differential Scanning Photocalorimeter.

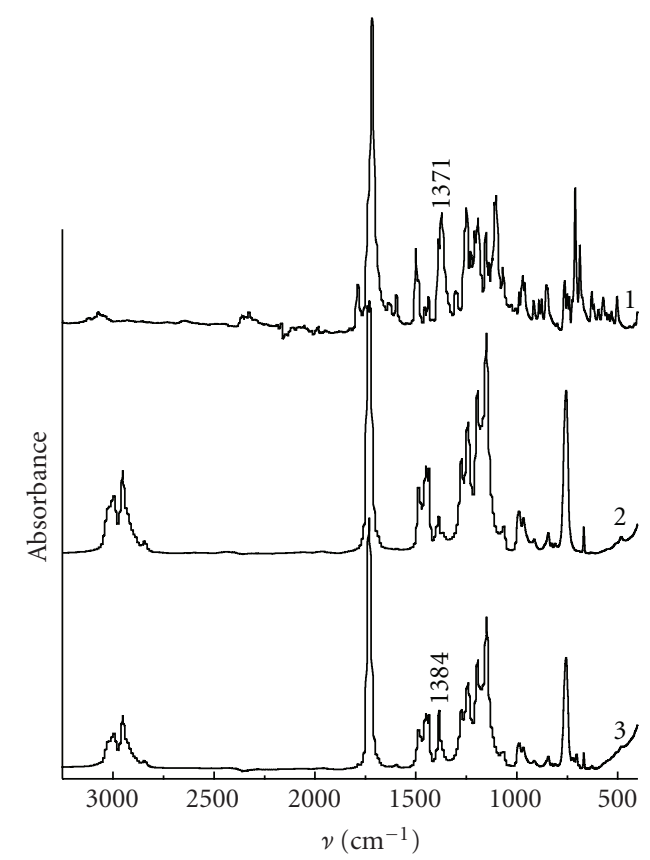

FIGURE 3: FTIR spectra of Diimide (1), PMMA (2), and PMMA obtained in the presence of $20 \mathrm{wt} . \%$ of Diimide (3).

2.4. Real-Time Infrared Spectroscopy (RT-FTIR). RealTime Fourier-Transform Infrared (RT-FTIR) spectra were obtained with "Spectrum GX System FTIR spectrometer, Perkin Elmer Instruments." This method allows estimation of the polymerization kinetics by measuring the reduction in intensity of absorption bands typical to double bonds in the monomer: $\mathrm{C}-\mathrm{H}$ out-of-plane vibrations at double bond and stretching vibrations of $\mathrm{C}=\mathrm{C}$ bond.

2.5. Bulk Photopolymerizaton. The solutions of monomers containing Pht (3wt.\% or $5 \mathrm{wt} . \%$ ) and various additives were exposed to UV-irradiation with light intensity of $31.5 \mathrm{~mW} \mathrm{~cm}^{-2}$. Polymerization was carried out at room temperature; irradiation time was 30 minutes. 


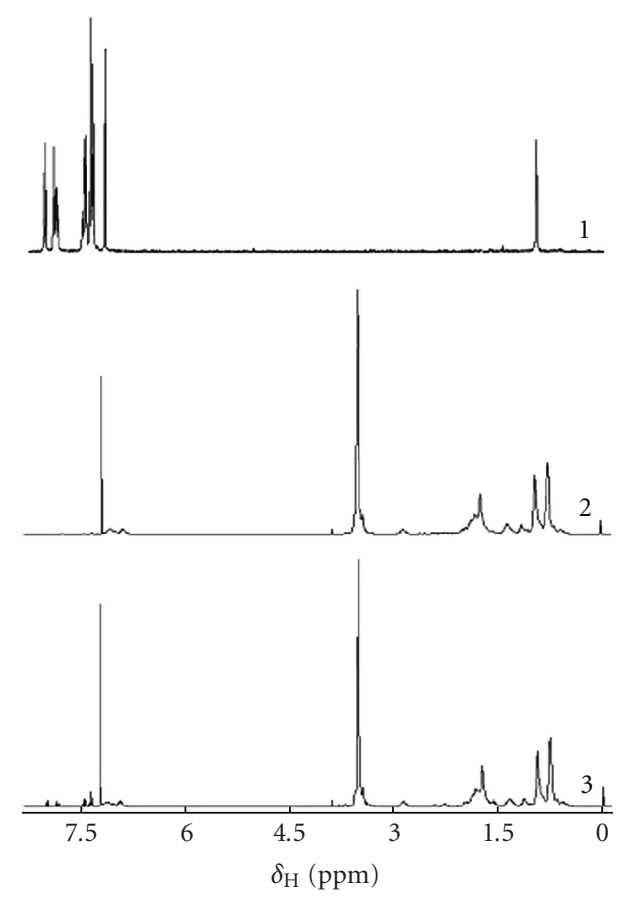

Figure 4: ${ }^{1} \mathrm{H}$ NMR spectra of Diimide (1), PMMA (2), and PMMA obtained in the presence of $20 \mathrm{wt} . \%$ of Diimide (3).

The maximum quantity of an additive compound was limited by the solubility of the monomer, and the viscosity of the monomer solution obtained. To achieve better homogenization the Pht was introduced first, and the PHA was then added. Polymers obtained from polymerization of methyl methacrylate were isolated by the precipitation from chloroform solution using methanol. The polymers were dried under vacuum at $70-80^{\circ} \mathrm{C}$. The isolation of polymers using ethyl acrylate (PEA) as vinyl monomer was carried out by the evaporation of chloroform from polymer solutions in a Petri dish.

2.6. Characterization Methods and Property Measurements. ${ }^{1} \mathrm{H}$ and ${ }^{13} \mathrm{C}$ NMR spectroscopy analysis was performed on a Bruker-AC $250 \mathrm{MHz}$ using $\mathrm{CDCl}_{3}$ as the solvent.

Dynamic thermogravimetric analysis (TGA) was performed in nitrogen atmosphere on a analyzer TGA Q50 at the heating rate $5^{\circ} \mathrm{C} \mathrm{min}^{-1}$.

Size exclusion chromatography (SEC) analyses of the samples were carried out on a Spectra Physics apparatus, using polystyrene standards for calibration and tetrahydrofuran as a carrier solvent at $30^{\circ} \mathrm{C}$ with a flow rate of $1 \mathrm{~mL} \mathrm{~min}^{-1}$.

2.7. Electron Spin Resonance (ESR). ESR spectra were recorded on a Varian E-12A spectrometer. The required quantity of AIBN, ND, MNP, Diimide, or phenyl benzoate was dissolved in a small amount of dichloromethane or in a mixture of dichloromethane with the monomer (EA or styrene). Reaction solutions were degassed in glass vials and irradiated at $\sim 20^{\circ} \mathrm{C}$ using a DRSh-1000 lamp directly in the resonator of the spectrometer. A band with $\lambda=366 \mathrm{~nm}$ was isolated through a glass color filter. The standard of firm "Varian" $g=2.0028$ has been utilized as the standard for calculation of $g$-factors of identified radicals. Spectra have been simulated using the program "SimFonia."

\section{Results and Discussion}

MMA and ethyl acrylate (EA) were used, as vinyl monomers. High (PI 1) and low molecular (PI 2) weight polyimides, polyarylate (PAr), and Diimide have been investigated as the compounds added to the monomers.

3.1. Photopolymerization of MMA and EA in the Presence of PIs, PAr, and Diimide. Weight ratio of PI and MMA was varied from 5 : 95 to 42 : 58. The amount of PI 1 and PI 2 introduced was no more than $15 \mathrm{wt} . \%$ and 42 wt.\%, respectively, and was limited by the extremely high viscosity of the resulting monomer solutions containing PI. Polymerization of MMA in the presence of model compound (Diimide) has been investigated in order to determine the exact PI chemical species involved in the MMA photopolymerization.

PAr was also used as the additive in spite of its low solubility (only $5 \mathrm{wt} \%$ PAr was soluble in MMA), to compare the influence of various PHA on the kinetics of unsaturated monomer photopolymerization and on the properties of polymer systems formed.

Autocatalytic model have been used for determination of kinetic parameters. This method is described in details in [15].

The added compounds influence strongly the kinetic curves of MMA polymerization. Thus, the rate of polymerization decreases in series PI $1>$ PI $2>$ Diimide (Figure 1(a)). It has been shown by the example of addition of PI 2 that the rate of polymerization decreases as the amount of compound introduced into the monomer solution increases from 5 wt.\% up to $42 \mathrm{wt} . \%$ (Figure 1(b)). It is evident that viscosity is not the only factor that influences the kinetics of MMA polymerization. Most likely, the interactions of the growing PMMA radical and/or a radical formed upon decomposition of Pht by molecules of the added compound also influence the kinetics of MMA polymerization. As a result less reactive radicals are formed which reduce the MMA polymerization rate in the presence of these compounds. Thus, Diimide and PI 2 decrease, but PI 1 accelerates the process of MMA polymerization. Apparently, this latter effect is determined by the viscosity factor which results in an increased polymerization rate with an insignificant content of high molecular PI 1.

Activation energy of reaction $\left(E_{a}\right)$ has been calculated from experimentally obtained temperature dependence of polymerization rate constants (Table 1), using the Arrhenius equation. The determined value of activation energy for MMA polymerization $\left(8.1 \mathrm{~kJ} \mathrm{~mol}^{-1}\right)$ has the good agreement with results published by Lecamp et al. $\left(2.2 \mathrm{kcal} \mathrm{mol}^{-1}=\right.$ $9.2 \mathrm{~kJ} \mathrm{~mol}^{-1}$ ) [16]. The difference in $0.9 \mathrm{~kJ} \mathrm{~mol}^{-1}$ is probably due to using bifunctional monomer in the paper cited above. 


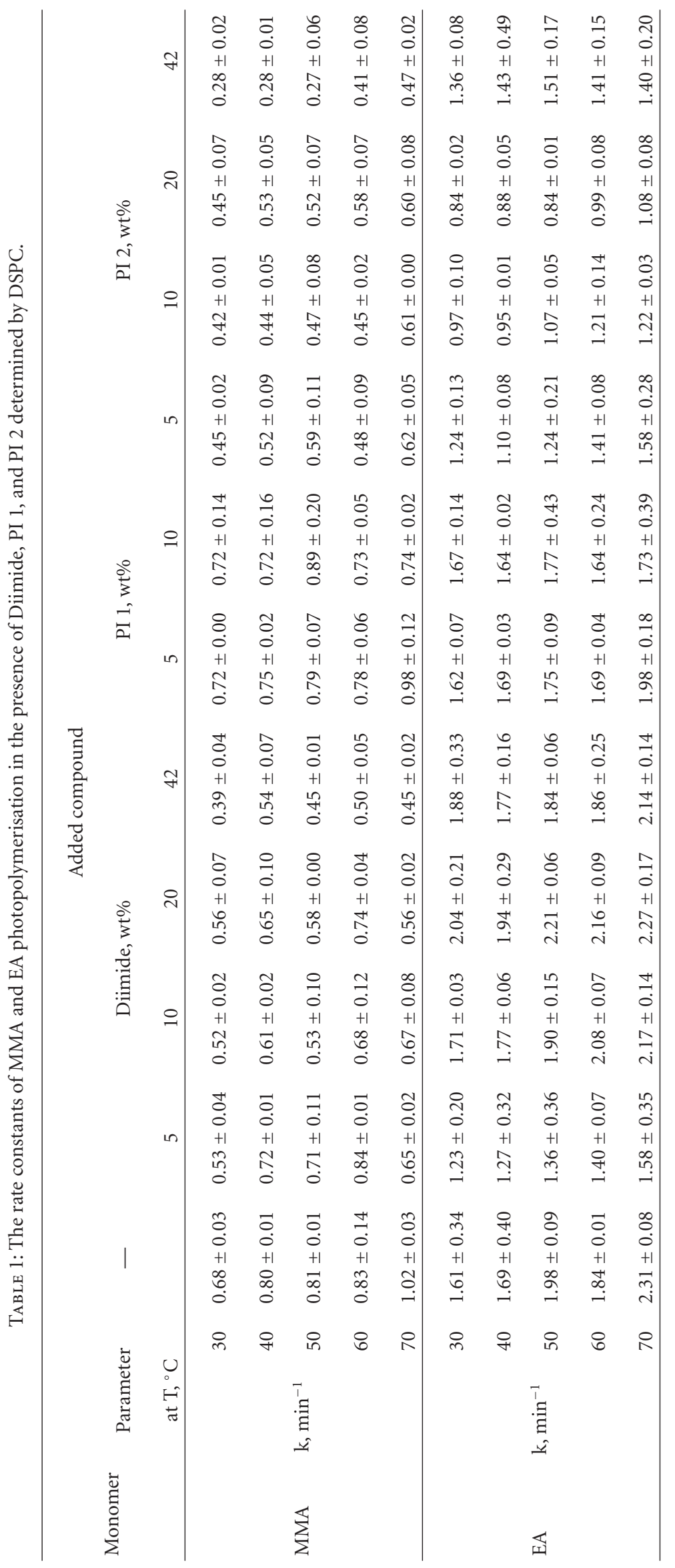


As can be seen from Table 2, introduction of additives to MMA involves a reduction of the polymerization activation energy. Increasing their content in the initial mixture results in the further decrease of $E_{a}$. Nevertheless, behavior specific to each introduced compound has been observed. On the one hand a more than sixfold reduction of $E_{a}$ was obtained, using as an additive $10 \mathrm{wt} \%$ of PI 1 (maximum possible concentration), compared to the $E_{a}$ for pure MMA. On the other hand, addition of the maximum possible amount of PI $2(42 \mathrm{wt} \%)$ drastically increases the $E_{a}$ of MMA photopolymerization.

A peculiar conduct of the solutions containing various amounts of Diimide has been observed. A marked reduction of $E_{a}$ of MMA polymerization takes place upon introduction $5 \mathrm{wt} \%$ of Diimide (Table 2). An increase in the content of Diimide causes only a slight further decrease of $E_{a}$.

In our earlier work it was shown that both PAr and PI cause significant changes in the kinetics of thermal polymerization of vinyl monomers [4] and in the properties of the polymers formed $[3,5]$.

The results of a kinetic parameters calculation for MMA polymerization in the presence of PAr do not allow us to compare it unambiguously with those for the PI systems. For instance, rate of MMA polymerization increases to a greater degree upon introduction of PAr ( $5 \mathrm{wt} \%)$ than upon addition of PI 1 to the system. $E_{a}$ of this system, compared to $E_{a}$ of pure MMA, increases only in the presence of Pht as has been observed exclusively earlier when using $42 \mathrm{wt} \%$ of PI 2 (Table 2).

The MMA polymerization results obtained by the calorimetric study correlate well with those obtained by RT-FTIR.

For (meth)acrylates the characteristic bands are at $812 \mathrm{~cm}^{-1}$ (out-of-plane vibrations of $\mathrm{C}-\mathrm{H}$ at double bond) and $1635 \mathrm{~cm}^{-1}$ (stretching vibrations of double bond $\mathrm{C}=\mathrm{C}$ ) [17-19]. The conversion of MMA upon irradiation has been calculated via absorbance intensity of the band at $1635 \mathrm{~cm}^{-1}$. One can see from Figure 2 (curve 2) that the introduction $10 \mathrm{wt} \%$ of PI 1 leads to a drastic increase in the polymerization rate while the addition $10 \mathrm{wt} \%$ of Diimide markedly slows down the photopolymerization of MMA (curve 3), which agrees absolutely with the results from DPC.

It is known that EA has a higher reactivity than MMA and that it can dissolve PI. Polyethylacrylate (PEA) is an elastomer, so that both the homopolymer and its different copolymers find applications in various areas [20].

Using DSPC it has been established that the rate of EA photopolymerization in the presence of PI 2 and Diimide reduces, whereas the addition of PI 1 leads to increasing the polymerization rate due to the viscosity factor as was observed at the photopolymerization of MMA.

Dissolving $5 \mathrm{wt} \%$ of Diimide in the monomer results in the reduction of kinetic parameters of EA polymerization. However with increasing Diimide concentration the reaction constants of EA polymerization raise, which was not observed for photopolymerization of MMA. The concentration of PI 1 has no significant influence on the rate constant for EA polymerization (cf. the similar results for MMA).

$E_{a}$ of EA polymerizations decreases with an increase in the content of the dissolved compound and achieves the minimum value at the maximum amount of such compound (the only exception being the solutions with Diimide; see Table 2). The general tendency for $E_{a}$ to decrease with increasing content of Diimide is observed, despite the irregularity of this reduction.

The growing PEA radical is probably less sterically hindered than the PMMA radical, which promotes its interaction with molecules of added compounds, including Diimide, and so produces greater changes in the kinetics of EA polymerization.

To prove the formation of new radicals (participation of PHA) during the initiation and/or termination steps of the polymerization of vinyl monomers, the ESR spectroscopy technique of spin traps was utilized [21]. Diimide and phenyl benzoate were used as model compounds of PI and PAr, respectively. The results obtained are presented in Table 3 . It has been established that the addition of phenyl benzoate and Diimide results in the formation of new radicals which differ in their magnetic resonance parameters from the radicals which are detected in a reaction system without Diimide and phenyl benzoate. These radicals represent the secondary carbon-centered or acyl radicals which are caught by a spin trap (Table 3).

Thus, the results of ESR spectroscopy have confirmed the previously proposed [4] mechanism of copolymer formation by the interaction of reaction system radicals with functional groups of the PHA added to the monomer. The parameters of detected radicals are similar to those published earlier in [22-25].

\subsection{Characterization of (Co)polymers Based on PMMA and} PEA Obtained in the Presence of PI, PAr, and Diimide. Since Diimide does not precipitate when a large excess of methanol is added to the solution of the polymer, reprecipitation of the latter from chloroform with methanol, followed by multiple washing, should remove all unreacted Diimide. The study of the model system PMMA $-20 \mathrm{wt} \%$ of Diimide by FTIR has revealed changes in the spectra caused by Diimide, namely, an increased intensity of absorbance at $1370-1385 \mathrm{~cm}^{-1}$ owing to the $-\mathrm{N}<$ imide cycle (Figure 3 ).

The presence of Diimide in the obtained mixture PMMA and Diimide is also confirmed by ${ }^{1} \mathrm{H}$ and ${ }^{13} \mathrm{C}$ NMR (Figures 4 and 5): signals from Diimide being seen at 7.3-8.3, 120-140, and 165-166 ppm, respectively.

However, not all the Diimide added to the monomer takes part in the chemical interaction, as shown by comparison of the ${ }^{1} \mathrm{H}$ and ${ }^{13} \mathrm{C}$ NMR spectra of PMMA obtained in the presence $20 \mathrm{wt} \%$ of Diimide and a corresponding mechanical blend. The quantity of Diimide that reacted during the polymerization of MMA has been calculated by the comparison of peak intensities of Diimide, in the ${ }^{1} \mathrm{H}$ and ${ }^{13} \mathrm{C}$ NMR spectra for PMMA synthesized in the presence of Diimide, and the corresponding mixture of PMMA and Diimide. This value has been established to be $5.3 \pm 1.2 \mathrm{wt} \%$ (on PMMA). These results are in good accordance with the element analysis data for fluorine content: $\mathrm{F}$ is calculated (for $100 \mathrm{wt} \%$ PMMA plus $20 \mathrm{wt} \%$ Diimide) and found to be 3.20 wt. $\%$ and 0.78 wt. $\%$, respectively; that is, the content of Diimide in modified PMMA is $4.9 \mathrm{wt} \%$. Incomplete 
TABle 2: Activation energy of MMA and EA photopolymerization in the presence of DI, PI 1, PI 2, and PAr.

\begin{tabular}{|c|c|c|c|}
\hline \multicolumn{2}{|c|}{ Added compound, wt.\% } & \multicolumn{2}{|c|}{$E_{a}, \mathrm{~kJ} \mathrm{~mol}^{-1}$} \\
\hline & & MMA & EA \\
\hline - & - & $8.14 \pm 0.62$ & $6.99 \pm 0.15$ \\
\hline \multirow{2}{*}{ PI 1} & 5 & $6.08 \pm 0.69$ & $3.21 \pm 0.22$ \\
\hline & 10 & $1.27 \pm 0.17$ & $0.96 \pm 0.26$ \\
\hline \multirow{4}{*}{ PI 2} & 5 & $7.19 \pm 0.48$ & $6.68 \pm 0.48$ \\
\hline & 10 & $6.48 \pm 0.15$ & $6.39 \pm 0.32$ \\
\hline & 20 & $6.10 \pm 0.48$ & $5.57 \pm 0.31$ \\
\hline & 42 & $12.11 \pm 1.22$ & $0.34 \pm 0.04$ \\
\hline \multirow{4}{*}{ Diimide } & 5 & $5.00 \pm 0.02$ & $4.61 \pm 0.37$ \\
\hline & 10 & $4.78 \pm 0.44$ & $5.35 \pm 0.05$ \\
\hline & 20 & $4.00 \pm 0.17$ & $2.16 \pm 0.60$ \\
\hline & 42 & $4.42 \pm 0.30$ & $3.13 \pm 0.45$ \\
\hline PAr & 5 & $11.25 \pm 0.90$ & - \\
\hline
\end{tabular}

TABLE 3: ESR spectra data of nitroxyl radicals detected at irradiation of studied solutions. Solvent $-\mathrm{CH}_{2} \mathrm{Cl}_{2} ;[\text { Styrene }]_{0}$, [Phenyl benzoate $]_{0}$, $[\text { Diimide }]_{0},[\text { Ethyl acrylate }]_{0}=1 \mathrm{~mol} \mathrm{~L}{ }^{-1} ;[\mathrm{AIBN}]_{0},[\mathrm{MeCHBrC}(\mathrm{O}) \mathrm{OEt}]_{0},\left[\operatorname{Re}_{2}(\mathrm{CO})_{10}\right]_{0}=3 \times 10^{-3} \mathrm{~mol} \mathrm{~L}^{-1}$.

\begin{tabular}{|c|c|c|c|c|c|}
\hline \multirow{3}{*}{ Radical source } & \multirow{3}{*}{ Spin-Trap } & \multirow{3}{*}{ Detected radical } & \multirow{2}{*}{\multicolumn{2}{|c|}{ Hyperfine splitting }} & \multirow{3}{*}{$g$-Value } \\
\hline & & & & & \\
\hline & & & $a_{N}$ & $\mathrm{a}_{\beta-\mathrm{H}}$ & \\
\hline \multirow{2}{*}{$\begin{array}{l}\text { Styrene } \\
\text { AIBN }\end{array}$} & \multirow{2}{*}{$\mathrm{ND}^{*}$} & $\mathrm{Me}_{2}{ }^{\bullet} \mathrm{CCN}(\mathrm{R})$ & 12.8 & - & 2.0059 \\
\hline & & $\mathrm{RCH}_{2}{ }^{\bullet} \mathrm{CHPh}$ & 13.7 & 4.0 & 2.0059 \\
\hline Styrene & \multirow{3}{*}{ ND } & $\mathrm{R}$ & 12.8 & - & 2.0059 \\
\hline AIBN & & $\mathrm{PhCOCH}_{2}{ }^{\bullet} \mathrm{CHPh}$ & 13.7 & 5.2 & 2.0061 \\
\hline Phenyl benzoate & & $\mathrm{O}^{\bullet} \mathrm{CPh}$ & 7.2 & - & 2.0069 \\
\hline \multirow{2}{*}{$\begin{array}{l}\text { AIBN } \\
\text { Phenyl benzoate }\end{array}$} & \multirow{2}{*}{ ND } & $\mathrm{R}$ & 12.8 & - & 2.0059 \\
\hline & & $\mathrm{O} \bullet \mathrm{CPh}$ & 7.2 & - & 2.0069 \\
\hline \multirow{2}{*}{ Phenyl benzoate } & \multirow{2}{*}{$\mathrm{MNP}^{* *}$} & $\mathrm{O} \cdot \mathrm{CPh}$ & 8.0 & - & 2.0066 \\
\hline & & $\mathrm{PhC}(\mathrm{O}) \mathrm{O}^{\bullet} \mathrm{C}_{6} \mathrm{Bu}^{\mathrm{t}} \mathrm{H}_{5}$ & 14.2 & 2.7 & 2.0060 \\
\hline Styrene & & $\mathrm{A}^{* * *}$ & 13.7 & 8.2 & 2.0060 \\
\hline AIBN & ND & $\mathrm{B}^{* * *}$ & 13.7 & 4.2 & 2.0060 \\
\hline \multicolumn{6}{|l|}{ Diimide } \\
\hline AIBN & \multirow{3}{*}{ ND } & $\mathrm{R}$ & 12.9 & - & 2.0060 \\
\hline \multirow[t]{2}{*}{ Diimide } & & $\mathrm{B}^{* * *}$ & 13.8 & 4.0 & 2.0060 \\
\hline & & $\mathrm{O}{ }^{\bullet} \mathrm{CPh}$ & 5.4 & - & 2.0064 \\
\hline \multirow{2}{*}{ Diimide } & \multirow{2}{*}{ MNP } & $\cdot \mathrm{Bu}^{\mathrm{t}}$ & 15.7 & - & 2.0060 \\
\hline & & $\mathrm{B}^{* * *}$ & 15.0 & 3.7 & 2.0060 \\
\hline AIBN & \multirow{2}{*}{ ND } & $\mathrm{R}$ & 12.8 & - & 2.0059 \\
\hline Ethyl acrylate & & $\mathrm{RCH}_{2}{ }^{\bullet} \mathrm{CHC}(\mathrm{O}) \mathrm{OEt}$ & 13.6 & 8.0 & 2.0059 \\
\hline $\mathrm{MeCHBrC}(\mathrm{O}) \mathrm{OEt}$ & \multirow{3}{*}{ ND } & $\mathrm{A}^{* * *}$ & 13.6 & 8.2 & 2.0059 \\
\hline $\operatorname{Re}_{2}(\mathrm{CO})_{10}$ & & $\mathrm{~B}^{* * *}$ & 13.6 & 4.0 & 2.0059 \\
\hline Diimide & & & & & \\
\hline
\end{tabular}

\footnotetext{
* Nitrosodurene (ND)

**2-Methyl-2-nitrosopropane (MNP)

$* * *$ see the scheme and text.
} 


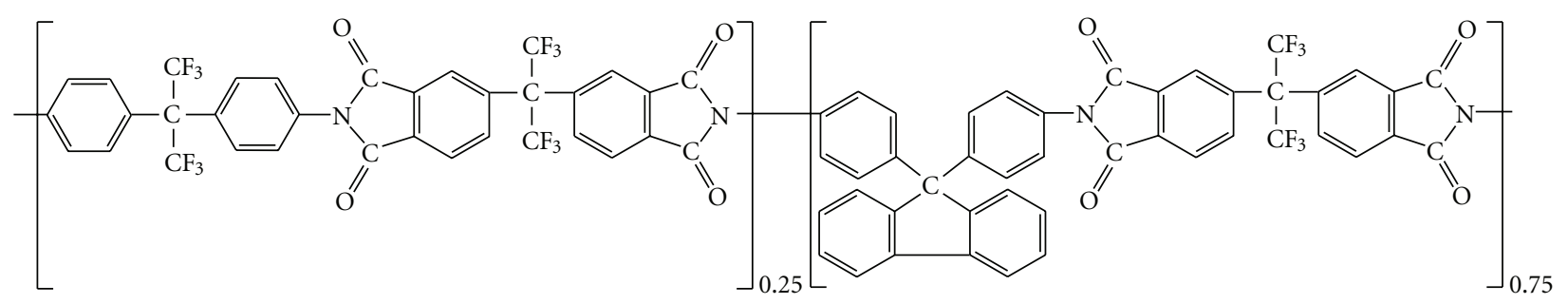

PI $1\left(\eta_{\text {inh }}=1.24 \mathrm{dL} / \mathrm{g}(\mathrm{MP})\right)$

PI $2\left(\eta_{\text {inh }}=0.29 \mathrm{dL} / \mathrm{g}(\mathrm{DMF})\right)$

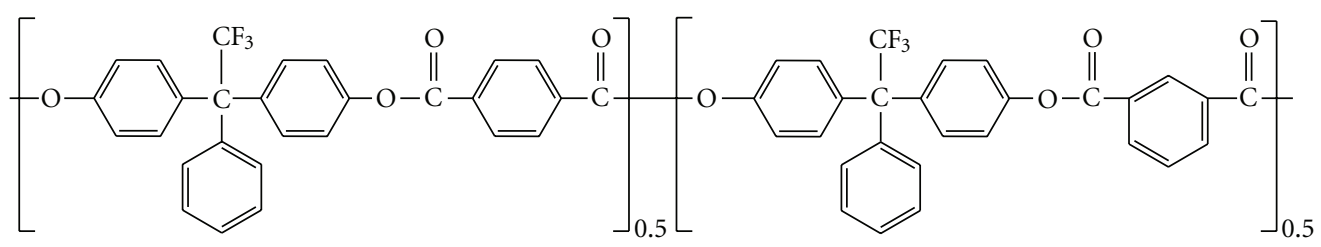

$\operatorname{PAr}\left(\eta_{\text {inh }}=0.71 \mathrm{dL} / \mathrm{g}(\mathrm{MP})\right)$<smiles>O=C1c2ccc(C(F)(C(F)(F)F)C(F)(F)F)cc2C(=O)N1c1ccccc1</smiles>

Diimide

Scheme 1

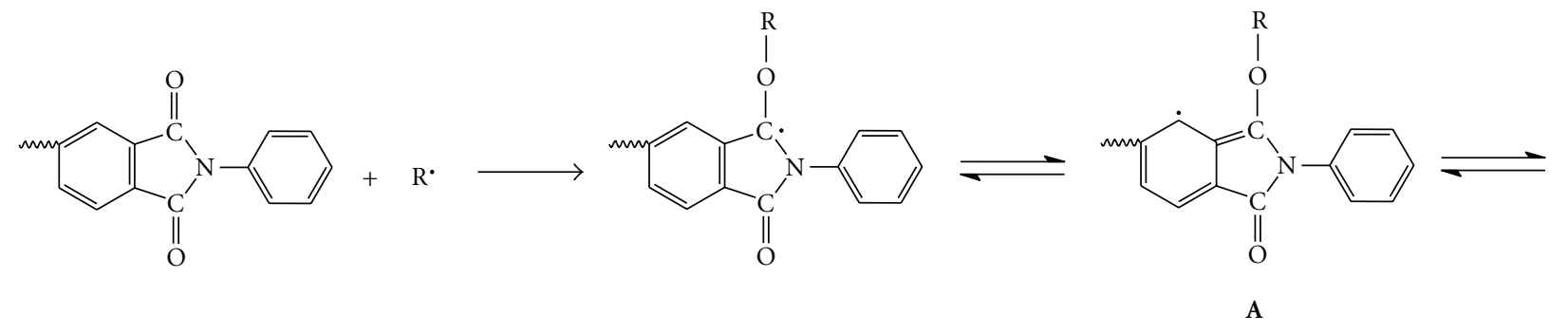<smiles>[R]OC1=C2C=C(C)CC=C2C(=O)N1c1ccccc1</smiles>

SCHeme 2 
<smiles>[R]OC(Oc1ccccc1C(=O)Oc1ccccc1C(=O)Oc1ccccc1OC1C=CC=CC1=C(O[R])OC1=CCC=CC1=C(O[R])Oc1ccccc1)=C1C=CC=CC1</smiles>

SCHEME 3

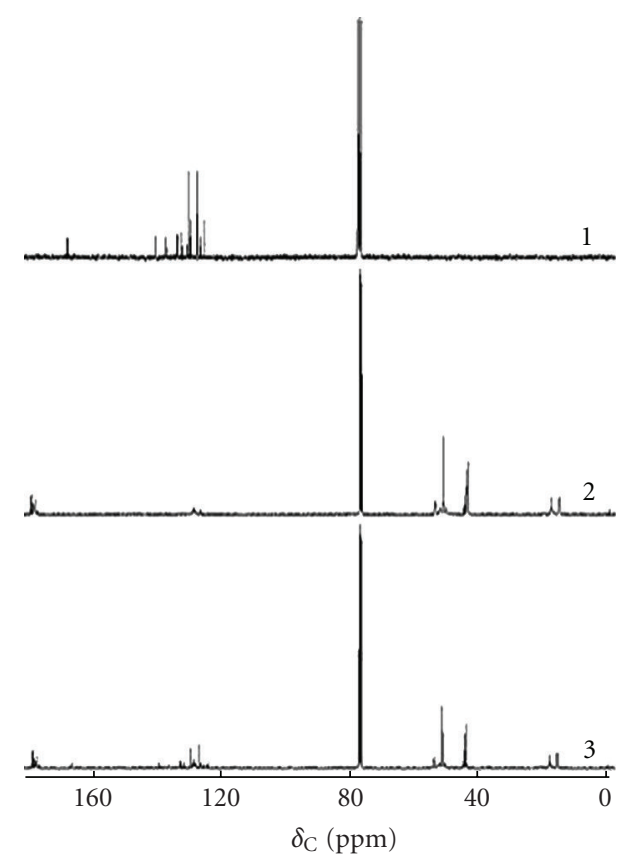

Figure 5: ${ }^{13} \mathrm{C}$ NMR spectra of Diimide (1), PMMA (2), and PMMA obtained in the presence $20 \mathrm{wt} . \%$ of Diimide (3).

interaction of Diimide with the radicals, formed during the photoinitiated polymerization of MMA, is also indicated by kinetic investigations.
It is necessary to pay attention to some features of the polymers based on PEA. Thus, for photopolymerization of EA containing PI 2 (20 wt.\% and $42 \mathrm{wt} . \%)$ and PI 1 ( $5 \mathrm{wt} \%$ ), the samples obtained are gel-like polymers soluble in chloroform only at intense stirring. However, the gel containing $11 \mathrm{wt} \%$ of PI 1 cannot be dissolved. Probably, the three-dimensional network formation is due to repeated addition of a growing PEA macroradical to molecules of introduced compound as well as to multiple participation of PI macromolecules in this process.

At the same time the polymer samples, containing $20 \mathrm{wt} . \%$ and $42 \mathrm{wt} . \%$ of PI 2, are precipitated upon adding a chloroform solution to methanol. The presence of PEA in each sample is confirmed by the FTIR spectra which show the characteristic bands for PEA at 2981, 1177, 1161, 1025, and $853 \mathrm{~cm}^{-1}$ (Figure 6). It should be noted that unmodified PEA is not precipitated from a chloroform solution by methanol.

The polymer samples obtained in the presence of Diimide, PI 1, and PI 2 are differed in an increased thermal stability, compared to pure PMMA and PEA (Table 4). As one can see from the results given in Table 4 even the addition of $5 \mathrm{wt} \%$ model Diimide, PI 1, PI 2, or PAr results in a increase in the $10 \%$ weight loss temperature $\left(\mathrm{T}_{10 \%}\right)$ for these sample on $35,50,60$, and $20^{\circ} \mathrm{C}$, compared to unmodified PMMA. The maximum increase of $\mathrm{T}_{10 \%}\left(85^{\circ} \mathrm{C}\right)$ is achieved when $42 \mathrm{wt} \%$ of PI 2 is added.

The mechanical blends of PMMA and $20 \mathrm{wt} \%$ of Diimide, PMMA, and $20 \mathrm{wt} \%$ of PI 2 prepared from common solutions have precisely the same $\mathrm{T}_{10 \%}$ as unmodified 
TABLE 4: 10\% weight loss temperature of polymers obtained by polymerization of MMA and EA in the presence of DI, PI 1, PI 2, and PAr.

\begin{tabular}{|c|c|c|c|}
\hline \multicolumn{2}{|c|}{ Added compound, wt $\%$} & \multicolumn{2}{|c|}{$\mathrm{T}_{10 \%}\left({ }^{\circ} \mathrm{C}\right)$ of $(\mathrm{co})$ polymer based on: } \\
\hline & & PMMA & PEA \\
\hline- & - & 210 & 320 \\
\hline \multirow{4}{*}{ Diimide } & 5 & 245 & 335 \\
\hline & 10 & 245 & 335 \\
\hline & 20 & $250(210)^{*}$ & 340 \\
\hline & 42 & 225 & 330 \\
\hline \multirow{3}{*}{ PI 1} & 5 & 260 & 345 \\
\hline & 10 & 250 & $345(345)^{* *}$ \\
\hline & 15 & 270 & - \\
\hline \multirow{4}{*}{ PI 2} & 5 & 270 & 345 \\
\hline & 10 & 270 & 345 \\
\hline & 20 & $280(210)^{*}$ & 350 \\
\hline & 42 & 295 & $340(345)^{* * *}$ \\
\hline \multirow[t]{4}{*}{ PAr } & \multirow[b]{2}{*}{ Diimide } & 230 & - \\
\hline & & \multicolumn{2}{|c|}{$335^{* * * *}$} \\
\hline & PI 1, PI 2 & \multicolumn{2}{|c|}{$525^{* * * *}$} \\
\hline & & \multicolumn{2}{|c|}{$470^{* * * *}$} \\
\hline
\end{tabular}

For the comparison $\mathrm{T}_{10 \%}$ of

* Homopolymers mixture prepared from common solution;

** Gel fraction;

*** Copolymer precipitated from chloroform solution into methanol;

$* * * *$ Used PHA and Diimide.

TABLE 5: SEC results of polymers based on MMA and EA.

\begin{tabular}{|c|c|c|c|}
\hline Sample & $M_{n} \times 10^{-3}$ & $M_{w} \times 10^{-3}$ & $M_{w} / M_{n}$ \\
\hline PMMA* & 12.6 & 27.8 & 2.2 \\
\hline MMA + 20 wt. $\%$ Diimide & 21.9 & 49.4 & 2.3 \\
\hline MMA + 10 wt. $\%$ PI 1 & 28.6 & 96.7 & 3.4 \\
\hline MMA + 20 wt. $\%$ PI 2 & 31.6 & 75.7 & 2.4 \\
\hline MMA + 5 wt. $\%$ PAr & 16.0 & 34.6 & 2.2 \\
\hline PEA* & 39.7 & 107.6 & 2.7 \\
\hline EA +11 wt. $\%$ Diimide & 56.2 & 143.1 & 2.6 \\
\hline $\mathrm{EA}+42$ wt. $\%$ Diimide & 62.6 & 138.4 & 2.2 \\
\hline $\mathrm{EA}+5$ wt. $\%$ PI 1 & 86.9 & 348.4 & 4.0 \\
\hline $\mathrm{EA}+11$ wt.\% PI 1 & 70.3 & 252.2 & 3.6 \\
\hline $\mathrm{EA}+5$ wt. $\%$ PI 2 & 50.9 & 269.2 & 5.3 \\
\hline $\mathrm{EA}+11$ wt. $\%$ PI 2 & 24.9 & 200.6 & 8.1 \\
\hline $\mathrm{EA}+20$ wt. $\%$ PI 2 & 42.6 & 300.1 & 7.0 \\
\hline $\mathrm{EA}+42$ wt. $\%$ PI 2 & 55.1 & 300.2 & 5.5 \\
\hline PI $1 *$ & 186.7 & 345.5 & 1.9 \\
\hline PI $2 *$ & 31.5 & 54.0 & 1.7 \\
\hline PAr* & 54.5 & 99.9 & 1.8 \\
\hline
\end{tabular}

*For the comparison.

PMMA. Therefore, it can be concluded that this increase in the thermal stability of PMMA is due to the formation of copolymers and to extra intermolecular interactions.

The addition of PI 1, PI 2, and FI results in an increase of thermal stability of the copolymers, but not so significant as for PMMA (Table 4). The maximum increase of $\mathrm{T}_{10 \%}$ is $30^{\circ} \mathrm{C}$ at addition of $20 \mathrm{wt} \%$ of PI 2.

It is known that the mechanism of PEA thermal decomposition is not the same as the PMMA depolymerization process [26, 27]. Therefore, the most likely reason of the 


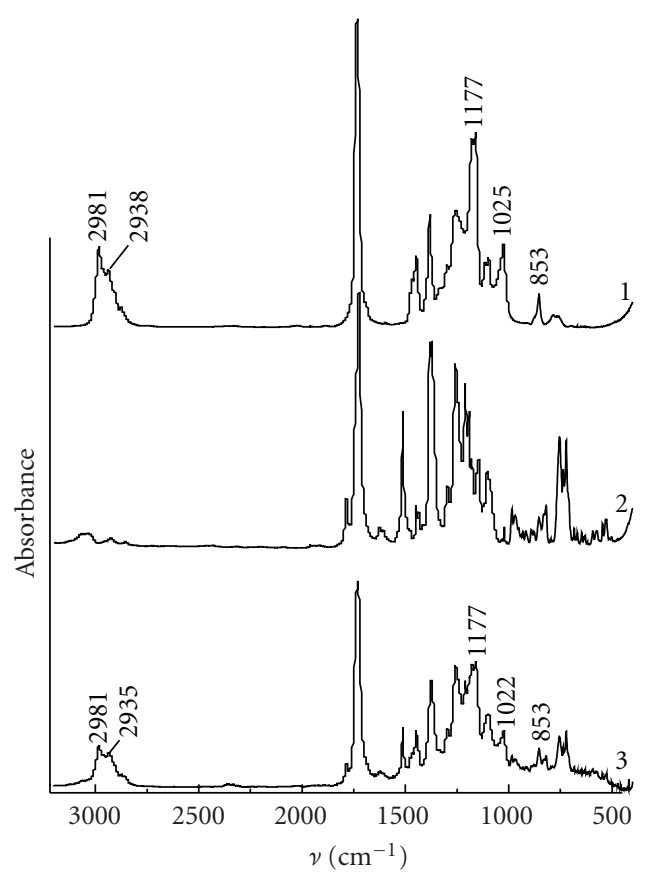

Figure 6: FTIR spectra of PEA (1), PI 2 (2), and PEA obtained in the presence $42 \mathrm{wt} \%$ of PI 2 and precipitated into methanol (3).

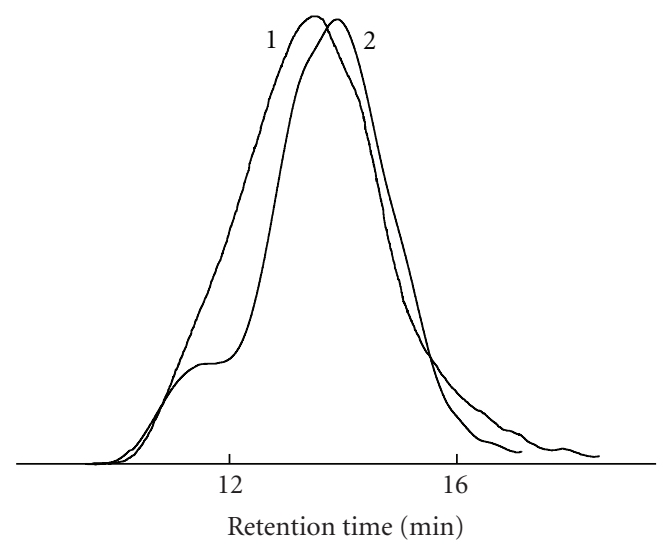

FIGURE 7: Chain-length distribution of PMMA obtained by photopolymerization of MMA in the presence $10 \mathrm{wt} \%$ of PI 1 (1) and relevant mixture (2).

increased thermal stability of polymeric samples based on PEA is the intermolecular interactions of PEA with Diimide, PI 1, and PI 2 rather than copolymer formation.

Molecular weights and polydispersity of the synthesized (co)polymers are given in Table 5. It should be noted that introduction of PI 1, PI 2, and PAr as well as the addition of Diimide results in the formation of higher molecular weight products from MMA polymerization. In this context, the polydispersity of the copolymers obtained increases (the exception is the sample containing $5 \mathrm{wt} \%$ of PAr). The higher polydispersity, most likely, indicates the formation of branched copolymers. Another confirmation of copolymer formation has been established by SEC for
PMMA with $10 \mathrm{wt} \%$ of PI 1 having a unimodal molecular weight distribution (MWD) in comparison with bimodal MWD for the corresponding mechanical blend (Figure 7).

It has been established that introduction of Diimide into EA results in the formation of polymers with higher molecular weights and lower polydispersity. The addition of PI owing to the obtaining branched copolymers (see above) promotes the formation of polymer systems, which are characterized by a much higher polydispersity index than unmodified PEA or PI itself.

\section{Conclusion}

It has been established by Fourier IR, NMR, SEC, and TGA methods that the radical photopolymerization of (meth)acrylates in the presence of dissolved polyheteroarylenes produces novel copolymers. The kinetic parameters of radical polymerization of unsaturated monomers in the presence of polyheteroarylenes and model compounds have been investigated by differential scanning photocalorimetry and IR spectroscopy. Using ESR spectroscopy novel radicals obtained by the addition of model compounds of polyheteroarylenes have been detected and a mechanism for the formation of copolymers has been proposed. The resulting copolymers have superior thermal properties to the relevant carbon-chain homopolymers.

\section{Acknowledgment}

D. A. Sapozhnikov gratefully acknowledges the French embassy in Russia for the support in carrying out the investigations in LEMP/MAO (University Montpellier 2) by the program "cotutelle."

\section{References}

[1] Ya. S. Vygodskii, A. A. Sakharova, and A. M. Matieva, "New polymeric systems prepared by polymerization of acrylates containing dissolved polyimides," Polymer Science, Series B, vol. 40, no. 7-8, pp. 282-285, 1998.

[2] Ya. S. Vygodskii, A. A. Sakharova, and A. M. Matieva, "Polymers based on fluoro(meth)acrylates and a fluorinated polyimide," Polymer Science, Series B, vol. 42, no. 3-4, pp. 6264, 2000.

[3] Ya. S. Vygodskii, A. M. Matieva, A. A. Sakharova, D. A. Sapozhnikov, and T. V. Volkova, "New polyheteroarylene based copolymers formulation," High Performance Polymers, vol. 13, no. 2, pp. S317-S326, 2001.

[4] Ya. S. Vygodskii, T. V. Volkova, A. A. Sakharova, D. A. Sapozhnikov, and A. M. Matieva, "Influence of poly(heteroarylenes) with different molecular masses on free-radical polymerization of methyl methacrylate," Polymer Science, Series A, vol. 44, no. 12, pp. 1249-1254, 2002.

[5] Ya. S. Vygodskii, A. M. Matieva, T. V. Volkova, A. A. Sakharova, and D. A. Sapozhnikov, "(Co)polymerization of styrene in the presence of polyheteroarylenes," Polymer Science, Series A, vol. 46, no. 4, pp. 352-360, 2004.

[6] Ya. S. Vygodskii, T. V. Volkova, A. A. Sakharova, D. A. Sapozhnikov, G. G. Nikiforova, and M. I. Buzin, "Threedimensional copolymerization of methyl methacrylate and 
allyl methacrylate in the presence of aromatic polyimide," Polymer Science, Series A, vol. 46, no. 7, pp. 681-687, 2004.

[7] Ya. S. Vygodskii, T. V. Volkova, A. A. Sakharova, D. A. Sapozhnikov, G. G. Nikiforova, and A. M. Matieva, "Three-dimensional free-radical copolymerization of methyl methacrylate with diunsaturated monomers in the presence of an aromatic polyimide," Polymer Science, Series A, vol. 48, no. 7, pp. 683-688, 2006.

[8] L. F. Thompson, C. G. Wilson, and M. J. Bowden, Introduction to Microlithography: Theory, Materials and Processes, American Chemical Society Symposium Series no. 219, American Chemical Society, Washington, DC, USA, 1983.

[9] C. E. Hoyle, in Radiation Curing Science and Technology, S. P. Pappas, Ed., Plenum Press, New York, NY, USA, 1992.

[10] A. Reiser, Photoreactive Polymers: The Science and Technology of Resist, John Wiley \& Sons, New York, NY, USA, 1989.

[11] S. Tazuke, Developments in Polymer Photochemistry. Vol. 3, Applied Science Publishers, London, UK, 1982.

[12] S. P. Pappas, "Photopolymerization," in Encyclopedia of Polymer Science and Engineering. Vol. 11, pp. 186-212, John Wiley \& Sons, New York, NY, USA, 1988.

[13] M. J. M. Abadie, V. Yu. Voytekunas, A. M. Matieva, and Ya. S. Vygodskii, "Photopolymerization of methyl methacrylate in the presence of polyimide," Polymer Science, Series B, vol. 45, no. 3-4, pp. 67-70, 2003.

[14] S. V. Vinogradova, V. A. Vasnev, and Ya. S. Vygodskii, "Cardo polyheteroarylenes. synthesis, properties, peculiarities," Uspekhi Khimii, vol. 65, no. 3, pp. 266-295, 1996, (Chem Abstr 1996, 125, 87247g).

[15] V. Yu. Voytekunas, F. L. Ng, and M. J. M. Abadie, "Kinetics study of the UV-initiated cationic polymerization of cycloaliphatic diepoxide resins," European Polymer Journal, vol. 44, no. 11, pp. 3640-3649, 2008.

[16] L. Lecamp, B. Youssef, C. Bunel, and P. Lebaudy, "Photoinitiated polymerization of a dimethacrylate oligomer: 2 . Kinetic studies," Polymer, vol. 40, no. 6, pp. 1403-1409, 1999.

[17] E. Selli and I. R. Bellobono, in Radiation Curing in Polymer Science and Technology, J. P. Fouassier and J. F. Rabek, Eds., Elsevier Applied Science, London, UK, 1993.

[18] M. Jöhnck, L. Müller, A. Neyer, and J. W. Hofstraat, "Quantitative determination of unsaturation in photocured halogenated acrylates and methacrylates by FT-IR and Ramanspectroscopy and by thermal analysis," Polymer, vol. 40, no. 13, pp. 3631-3640, 1999.

[19] M. Jöhnck, L. Müller, A. Neyer, and J. W. Hofstraat, "Copolymers of halogenated acrylates and methacrylates for the application in optical telecommunication: optical properties, thermal analysis and determination of unsaturation by quantitative FT-Raman and FT-IR spectroscopy," European Polymer Journal, vol. 36, no. 6, pp. 1251-1264, 2000.

[20] P. H. Starmer and F. W. Wolf, Encyclopedia of Polymer Science and Engineering. Vol. 1, John Wiley \& Sons, New York, NY, USA, 1985.

[21] M. J. Perkins, "Spin trapping," in Advances in Physical Organic Chemistry, 17, V. Gold and D. Bethell, Eds., pp. 1-64, Academic Press, New York, NY, USA, 1980.

[22] S. Terabe, K. Kuruma, and R. Konaka, "Spin trapping by use of nitroso-compounds-part VI: nitrosodurene and other nitrosobenzene derivatives," Journal of the Chemical Society, Perkin Transactions 2, no. 9, pp. 1252-1258, 1973.
[23] T. Sato, M. Abe, and T. Otsu, "Application of spin trapping technique to radical polymerization, 15 . Photo-decomposition of dibenzoyl disulfide and evaluation of relative reactivities of vinyl monomers toward the benzoylthiyl radical," Die Makromolekulare Chemie, vol. 178, no. 7, pp. 1951-1958, 1977.

[24] T. Sato and T. Otsu, "Application of spin trapping technique to radical polymerization, 14 . Initiation reaction of vinyl monomers with the tert-butoxyl radical and evaluation of monomer reactivities," Die Makromolekulare Chemie, vol. 178, no. 7, pp. 1941-1950, 1977.

[25] S. Forshult, C. Lagercrantz, and K. Torssel, "Use of Nitroso Compounds as Scavengers for the Study of Short-Lived Free Radicals in Organic Reactions," Acta Chemica Scandinavica, vol. 23, pp. 522-530, 1969.

[26] O. Marek and M. Tomka, Acrylic Polymers, Khimiya, Moscow, Russia, 1966.

[27] S. I. Madorsky, Thermal Degradation of Organic Polymers, Interscience, New York, NY, USA, 1964. 

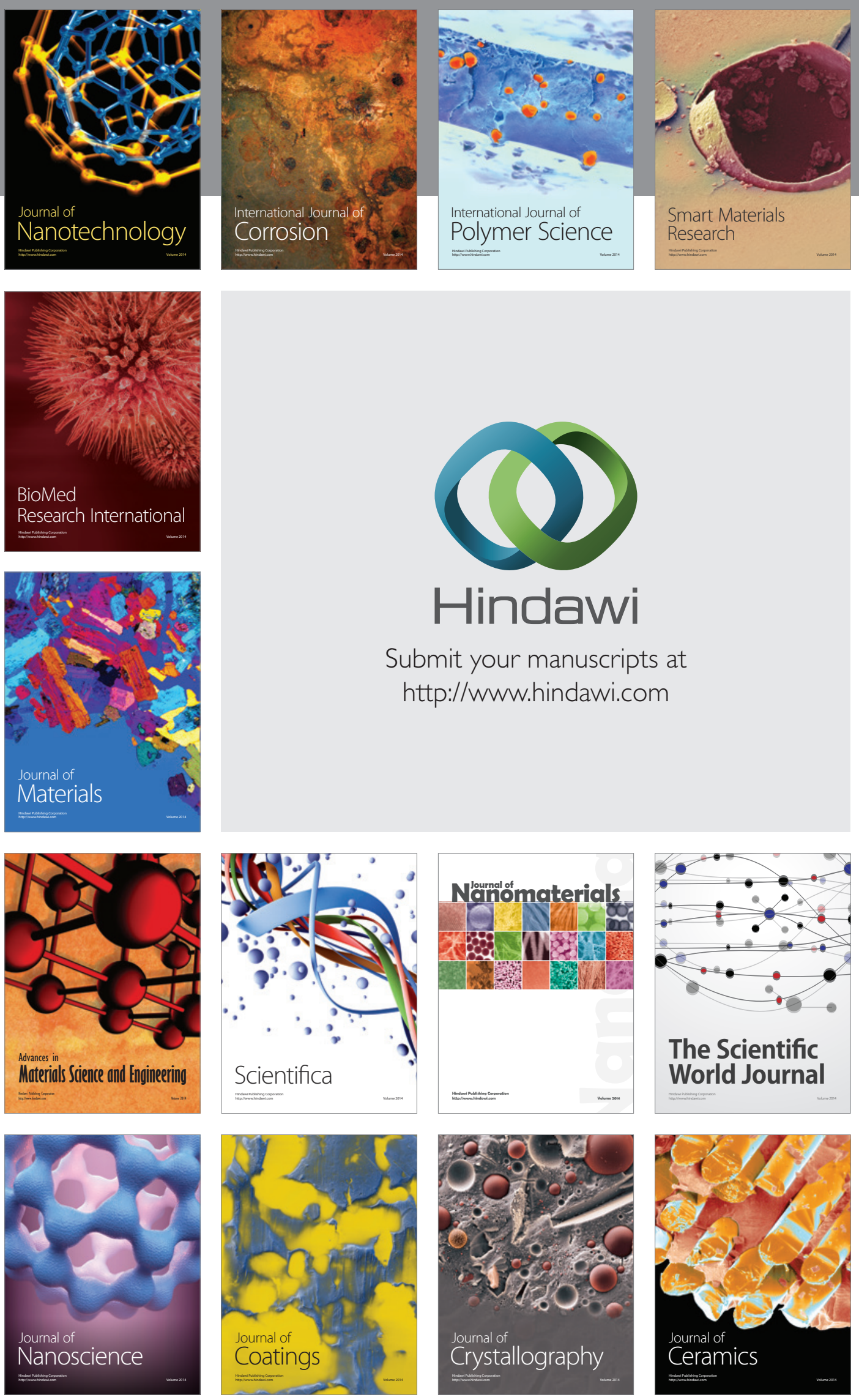

The Scientific World Journal

Submit your manuscripts at

http://www.hindawi.com

\section{World Journal}

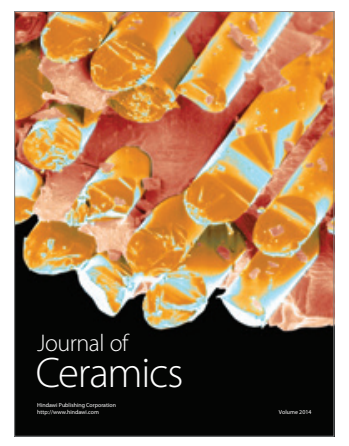

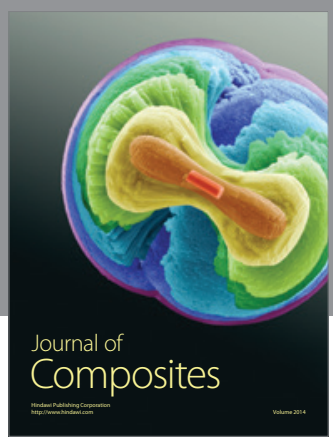
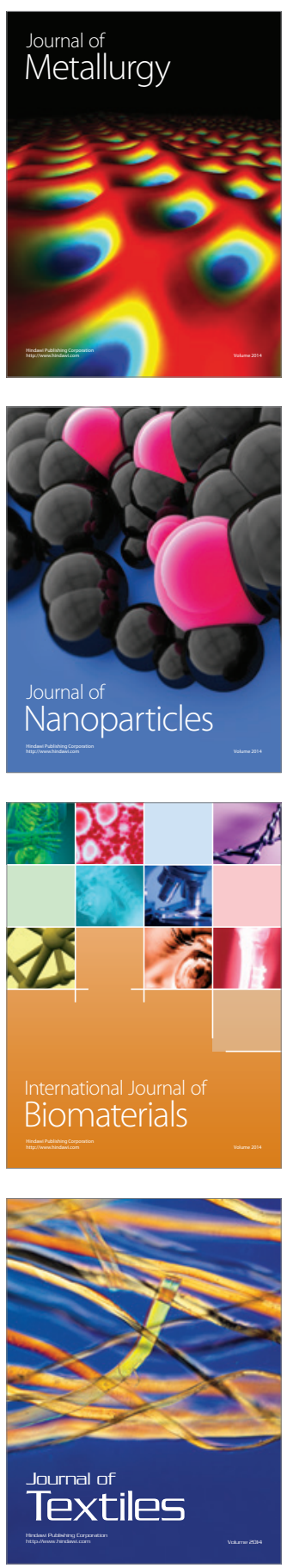